\title{
TARJETAS DE CRÉDITO EN COLOMBIA: LEYES, INSTITUCIONES Y EFECTOS $^{\mathrm{a}}$
}

\author{
María Fernanda Palomino-Martínez
}

Recibido: abril, 2019 • Aceptado: agosto, 2019

Cómo citar: Palomino-Martínez, M. F. (2019). Tarjetas de crédito en Colombia: leyes, instituciones y efectos. Ciencia, Economía y Negocios, 3(1), 59-86. Doi: https://doi.org/ 10.22206/ceyn.2019.v3i1.pp59-86

\section{Resumen}

En los últimos años, los sucesivos gobiernos colombianos han expedido un importante número de normas legales y han implementado una serie de políticas públicas que redefinieron el acceso a más personas al mercado crediticio. Desde el año 2006, cada Plan Nacional de Desarrollo (PND) incluyó un acervo de politicas económicas encaminadas a flexibilizar las condiciones para adquirir créditos de consumo; una flexibilización que suponía dar facilidades de acceso a personas con cada vez menos capacidad económica para hacer frente a las obligaciones financieras contraídas. Este documento tratará de describir las normatividades y politicas públicas, instituciones y efectos que han dado lugar a la inclusión financiera en Colombia.

Palabras clave: inclusión financiera; politicas públicas; endeudamiento; tarjeta de crédito.

Códigos JEL: D14, G28, G40.

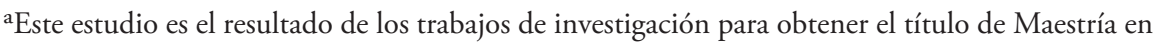
Gerencia Financiera y Tributaria de la Universidad Antonio Nariño (2017) y de la Maestría en Sociología de la Universidad del Valle (2019)

bPalomino-Martínez, M. F. Universidad del Valle. Dirección: Sede San Fernando, calle 4B \#36-00. T: (PBX) +57 2 3212100, Correo-e: maria.palomino@correounivalle.edu.co

ORCID: 0000-0002-8698-3946
}

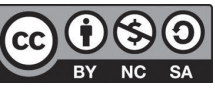




\title{
COLOMBIAN CREDIT CARDS: LAWS, INSTITUTIONS, AND EFFECTS
}

\author{
María Fernanda Palomino-Martínez
}

Received: april, 2019 • Accepted: August, 2019

\begin{abstract}
In recent years, successive Colombian governments have issued an important number of legal norms and have implemented a series of public policies that redefined the access to more people in the credit market. Since 2006, each National Development Plan (NDP) has included a plethora of economic policies aimed at making the conditions for acquiring consumption credits more flexible; a flexibilization that aimed to facilitate credit access for people with less economic capacity to face the contracted financial obligations. This document describe regulations and public policies, institutions and effects that have led to financial inclusion in Colombia.
\end{abstract}

Keywords: financial inclusion; public policies; indebtedness; credit card.

JEL Codes: D14, G28, G40. 


\section{La reorientación de las políticas}

Doña Lucy tiene más de 50 años, proviene de una familia de escasos recursos y baja escolaridad. Su sustento ha dependido sobre todo del trabajo informal: hace dieciocho ańos encontró otra forma de obtener ingresos cerca de su residencia, a las afueras de una pequeña universidad de Palmiraa: un platón con chontaduros", mangos, "minutos" (llamadas a celular) y ventas por catálogo. Con el tiempo, el platón se convirtió en una carreta que ahora le permite tener a la venta más productos (salpicón, pasabocas, agua...) y mejorar sus ingresos. Es un negocio estacional, pues la afluencia de estudiantes dura solo ocho meses al ańo; en los meses restantes se dedica a las ventas por catálogo. Pese a la informalidad, estacionalidad e incertidumbre del negocio, en el año 2012 un gran banco le ofreció una tarjeta de crédito con un límite de crédito de 500 dólares americanos. Además de poderla usar en cualquier comercio, la tarjeta le otorgaba beneficios en un supermercado. En el 2015, mientras hacía unas compras en un almacén de cadena, un asesor le ofreció la tarjeta CrediUno ${ }^{c}$ con cupo de 700 dólares con tan solo la verificación del documento de identidad — pues estas entidades revisan directamente en las bases de las centrales de riesgo para evaluar si un cliente es apto para recibir el crédito-. En la actualidad, Doña Lucy solo conserva la tarjeta CrediUno, pues los costos de la tarjeta de crédito de Colpatria eran onerosos.

Doña Lucy ha obtenido fácilmente tarjetas de crédito a pesar de no contar con estabilidad en sus ingresos, lo que lleva a preguntar, en primer lugar, cómo personas en tales condiciones económicas pueden acceder tan fácilmente a sistemas de crédito formal. Este caso muestra cómo las instituciones financieras están interesadas en aumentar su cuota de mercado

aPalmira es una ciudad intermedia del departamento del Valle del Cauca, Colombia; hace parte del área metropolitana de Cali, la tercera ciudad más importante del país. Palmira es reconocida por ser un epicentro agroindustrial ya que es sede de los principales ingenios azucareros del país. ${ }^{b}$ Fruto que se extrae de las palmeras. En otros países puede reconocerse con el nombre de: pejibaye, pupuña, pipire, pijuay, cachipay, pifá, pibá, chima o tembe.

${ }^{\mathrm{C}}$ Crediuno es una tarjeta de crédito dirigida a sectores de bajos recursos por cuanto expiden desembolsos crediticios con la demostración de unos mínimos ingresos. Este producto financiero pertenece a la compañía no bancaria Credivalores, que se especializa en sectores no atendidos por las entidades bancarias. 
dirigiendo ciertos productos a sectores que antes no habían tenido en consideración; ello les ha supuesto, entre otras cosas, modificar sus perspectivas sobre el riesgo. La asignación de tarjetas de crédito a personas con ingresos inferiores al salario mínimo, la posibilidad de reemplazar las garantías de pago con seguros expedidos por las mismas entidades financieras o el generoso aumento de los cupos sin solicitud previa de los clientes, son indicios de la reorientación de las políticas económicas de estas entidades, con la consecuente transformación de la infraestructura, la oferta y la demanda financiera.

Algunos estudios plantean que, entre los factores que acompañarían a estos cambios, están las políticas diseñadas por los Estados, dirigidas a incluir a más ciudadanos en el sistema financiero; unas directrices en las que han incidido también orientaciones políticas y económicas internacionales.

Por ejemplo, en Costa Rica, Chaves (2013) refiere que las políticas públicas han ido en dirección de desregular los mercados financieros para que las personas puedan acceder a más productos, por eso es necesario que se garanticen medidas que contrarresten la asimetría entre emisor y tarjetahabiente, asegurando el equilibrio en el sistema financiero ante la indudable exposición de riesgo existente. En Paraguay, la relación entre política pública y tarjeta de crédito se inscribe en que la agenda del gobierno apunta hacia la inclusión financiera, la mejora del sistema de pagos a través de tarjetas y la discusión sobre las formas de canalizar la reducción del impuesto al valor agregado por compras hechas con tarjetas de crédito (Pereyra, 2011). En Perú, Pachas (2011) señala la importancia de la adopción de medidas de carácter político orientadas a propiciar una mayor competencia de intermediarios, regular la elevada tasa de interés y garantizar la transparencia de información por parte de los bancos y entidades financieras que ofertan las tarjetas de crédito, con el fin de extender el mercado a otros segmentos de la población. En Chile, los derechos políticos ahora son interpretados por el Estado como derechos del consumidor (Han, 2011).

Cabe apuntar que en general el Estado ha provisto la promoción de los mercados financieros y la mercantilización del ciclo de vida, conduciendo a que el sistema financiero desarrolle productos para grandes segmentos de la población, después de años de discriminación. Esto ha permitido prácticas predatorias reflejadas en préstamos que condenan 
a individuos de bajos y medianos ingresos a una vida de deuda (Van der Zwan, 2014).

De igual forma, el poder creciente y sistémico de las instituciones financieras impregnan la vida cotidiana con nuevos productos que surgen de la creciente mercantilización de la trayectoria vital — deuda estudiantil, marketing de las tarjetas de crédito o las hipotecas-. Con esto se admite una importante expansión de las corporaciones financieras hacia la estrategia de dominar las finanzas personales (Blackburn, 2006, p. 40).

Adicional a lo anterior, organismos multilaterales como el Banco Mundial (BM) y el Fondo Monetario Internacional (FMI) han respaldado la iniciativa denominada inclusión financiera ${ }^{\mathrm{d}}$, como alternativa de financiación para las personas de bajos ingresos. Estas entidades han promovido que la inclusión financiera sea una prioridad para las autoridades estatales, los organismos reguladores y las instituciones de desarrollo en todo el mundo. La iniciativa de Acceso Financiero Universal 2020 (UFA 2020 por sus siglas en inglés) propuesta por el Banco Mundial, implica un compromiso político y coordinación entre los actores públicos y privados, con el fin de "crear un entorno normativo y regulatorio propicio que fomente la competencia, permitiendo a las instituciones bancarias y no bancarias innovar y ampliar el acceso a los servicios financieros innovadores, así como datos de alta calidad para la formulación de políticas". Este entorno también debe estar acompañado de regulaciones y medidas de protección del consumidor para asegurar la prestación responsable de los servicios financieros (Banco Mundial, 2017).

Conviene subrayar que otras organizaciones internacionales como la Alianza para la Inclusión Financiera (AFI) y el Centro para la Inclusión Financiera (CFI), se han venido consolidando como redes que facilitan el acceso a servicios financieros a la población que ha sido excluida. AFI señala que la inclusión financiera se desarrolla principalmente en tres dimensiones: 1) Acceso: posibilidad de acceder a servicios y productos de instituciones financieras; 2) Uso: profundidad o alcance del uso de servicios y productos financieros; 3) Calidad: en el sentido de propiciar

dEl Banco Mundial define que la inclusión financiera corresponde al acceso que tienen las personas y las empresas a una variedad de productos y servicios financieros útiles y asequibles que satisfacen sus necesidades (como pagos y transferencias, ahorro, seguros y crédito) y que son prestados de una manera responsable y sostenible (Banco Mundial, 2017, p. 1). 
un mayor bienestar a la población en cuanto al servicio o producto financiero. Colombia firmó en 2011 la declaración de Maya — primer acuerdo mundial de hacedores de política de países emergentes- que tiene por objeto desbloquear el potencial económico y social de la población más pobre a través de una mayor inclusión financiera (AFI, 2013). El Centro para la Inclusión Financiera (CFI) brinda soporte para que las instituciones financieras ofrezcan portafolios de bajos costos, altos niveles de seguridad, mejoras en la productividad, a través de la tecnología financiera (Fintech), la cual se convierte en un aliado estratégico para lograr inclusión financiera.

En el caso de Colombia, ¿han existido dichas políticas?, ¿`cuáles han sido?, ¿cómo se han ajustado a través del tiempo?, ¿cuál ha sido la efectividad de estas políticas? Para responder a esas preguntas, en este artículo ofrecemos, en primer lugar, la enumeración de las leyes y políticas desarrolladas en Colombia en los últimos años; a continuación, sigue la enumeración de las instituciones que se han ocupado de ponerlas en marcha; finalmente, se presenta un pequeño balance del impacto de esas políticas.

De acuerdo a lo anterior, este estudio de corte positivo pretende tres objetivos principales: describir un marco normativo e institucional que incluye cambios en la legislación del endeudamiento, teniendo como referente la tarjeta de crédito entre los años 2008 y 2017, reflexionar sobre los cambios que han abierto vías para la financiarización y, finalmente, que algunos resultados muestran una coevolución en el número de tarjetas existentes en el mercado; sin embargo, el alcance de la investigación no contiene instrumentos econométricos que puedan reconocer si hay correlación entre estas normatividades y el incremento en el número de tarjetas de crédito. Carecemos de datos que puedan señalar la expansión crediticia por estratificaciones sociales.

\section{Leyes y políticas colombianas para ampliar el crédito}

En primera instancia, en el Artículo 335 de la Constitución Política de Colombia (promulgada en el año 1991 y vigente en la actualidad) se plantea que, además de regular la actividad financiera, el Estado promoverá la "democratización del crédito" haciendo los empréstitos más asequibles para gran parte de la población. Sin embargo, a pesar de estar consignado 
en la Carta Política, no es sino en el año 2006 que se establece por primera vez alguna política pública para dar cumplimiento a este propósito y que aún sigue vigente. La figura 1 sintetiza en orden cronológico las normas legales que han coadyuvado a la expansión del crédito.

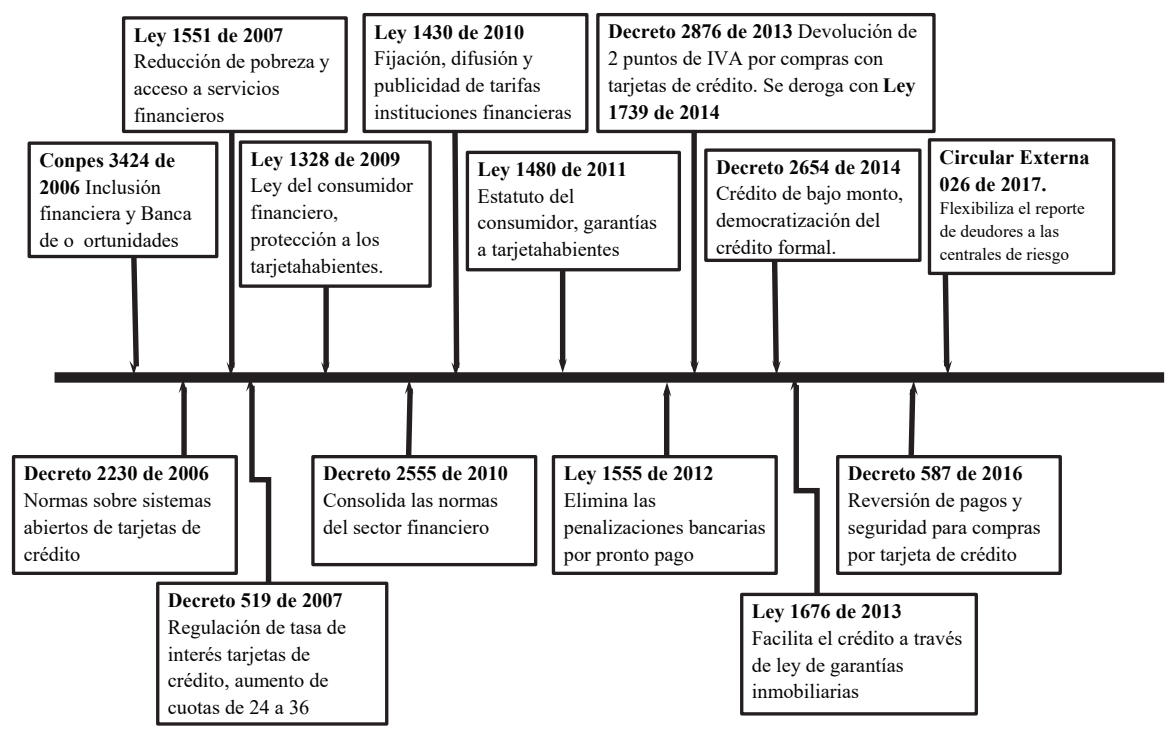

Figura 1. Resumen de las principales normatividades relacionadas con el uso de las tarjetas de crédito en Colombia.

Fuente: elaboración propia a partir de leyes y decretos de Colombia.

Con la expedición del Conpes 3424 (2006) se adoptó la política pública de Banca de las Oportunidades. Su objetivo fue crear las condiciones necesarias para facilitar el acceso al sistema financiero formal, mediante la provisión de crédito y otros servicios financieros a las poblaciones que generalmente han sido excluidas. Los alcances de esta reforma fueron: los corresponsales no bancarios; las cuentas de ahorro de bajo monto, las cuales están exentas del gravamen a los movimientos financieros GMF (en la actualidad 4 por mil), no obligadas a hacer inversiones forzosas y con requisitos simplificados de sistema integral en la prevención del lavado de activos para la apertura. Se incluyó también una reforma al régimen de garantías asegurando que los créditos pudieran ser cobrados 
de forma segura, predecible y transparente. Elementos indispensables para crear un ambiente favorable a la ampliación de la cobertura de créditos y para la disminución de sus costos (Conpes 3424, 2006).

De igual manera, se fortaleció el sistema de las centrales de riesgo. Esto implicó una reforma a la Ley Estatutaria sobre Habeas Data y la construcción de bases de datos nutridas de fuentes adicionales al sector financiero. Para tal efecto, se incorpora la información sobre pago de servicios públicos o arriendos, ya que en la mayoría de los casos es positiva y constituye la puerta de acceso al crédito de población no bancarizada (Conpes 3424, 2006).

La Ley 1151 (2007) (Plan Nacional de Desarrollo 2006-2010) o ley de reducción de la pobreza estuvo dirigida a soluciones eficaces contra la inequidad y la vulnerabilidad. Esta política se fijó como una acción de largo plazo, encaminada a crear las condiciones necesarias para facilitar el acceso y uso de servicios financieros integrales. Fortaleció la institucionalidad de Banca de las Oportunidades, las redes de entidades del sistema financiero, que incluye las cooperativas, las organizaciones no gubernamentales y las cajas de compensación familiar. Con esta directriz, se fomentó la intervención coordinada entre el sector público y el privado, pues las entidades financieras invirtieron el $96 \%$ del presupuesto para esta estrategia —aproximadamente 1 millón de dólares(Ley 1151, 2007).

La expedición de estar primeras leyes produce como efecto que más personas se conviertan en candidatos viables para los recursos e instrumentos que ofrece el mercado financiero, generando así otra fuente de ganancias para las entidades del sector. Al mismo tiempo, estas políticas facilitan las posibilidades de adquirir créditos de acuerdo con las necesidades y deseos de personas en condición de pobreza; estas transacciones están vinculadas con el grupo familiar, los códigos y valores que comparten (Müller, 2014, p. 21), de manera que la solidaridad familiar probablemente se convierte en una garantía de pago que el sistema financiero implícitamente detecta en los hogares pobres.

En el año 2007 se reitera que la tarjeta de crédito pertenece a la categoría de crédito de consumo a través del Decreto 519 (2007). En el artículo 4 de esta legislación se flexibiliza el manejo de la tarjeta de crédito modificando el plazo de los pagos, aumentando el término a 36 meses, 
derogando decretos anteriores que estipulaban un plazo máximo de 24 meses. Los pagos se amortizarían en el correspondiente período hasta por el valor total de cada utilización, en cuotas mensuales uniformes.

La Ley 1328 (2009) o ley del consumidor financiero. Con el objetivo de proteger el usuario del sistema financiero, esta normatividad incluyó: el Sistema de Atención al Consumidor Financiero (SAC), regulaciones al suministro de información al consumidor y estableció derechos y obligaciones de los clientes. Se consolida que cada entidad financiera tenga un Defensor del Consumidor Financiero. Con respecto a las tarjetas de crédito el Artículo 7 instituye para las entidades financieras, la recopilación de información y obtención de pruebas, en los casos de fraude, hurto o cualquier otra conducta castigable realizada mediante el uso de tarjetas crédito o débito, la realización de transacciones electrónicas o telefónicas, así como cualquier otra modalidad.

El Plan Nacional de Desarrollo 2010-2014 o Ley 1450 (2011), adoptó metas concretas de inclusión financiera y adicionó medidas para garantizar la oferta en regiones apartadas, diseñar productos adecuados para los diferentes segmentos poblacionales y promover la educación económica y financiera.

Seguidamente, la Ley 1555 (2012) elimina las penalizaciones de los bancos por el pago anticipado de obligaciones, lo que favorece a los consumidores financieros de varias maneras. La primera es que los clientes de productos financieros pueden pagar sus créditos cuando tienen excedentes de dinero, sin incurrir en costos adicionales al capital adeudado. La segunda es que los clientes pueden buscar alternativas para vender su cartera a la entidad financiera que ofrezca la tasa de interés más beneficiosa. En la actualidad, los deudores tienen la opción de encontrar en el mercado tasas de interés competitivas para la venta de sus obligaciones financieras.

Con el fin de estimular el uso de las tarjetas débito y crédito como medio de pago, fue adicionado el Artículo 850-1 al Estatuto Tributario Ley 863 (2003) a través del Decreto 2876 (2013). En el cual se establecía la devolución de dos puntos del IVA (impuesto al valor agregado) del $5 \%$ y $16 \%$ por compras con tarjetas débito y crédito. Esta medida causó un uso más eficiente del capital, mayor seguridad personal, y la reducción de la informalidad y evasión en el país. Además de beneficiar al tarjetahabiente, generó información para la administración tributa- 
ria, contribuyendo al control de las operaciones. No obstante, con la Reforma Tributaria de 2014, este beneficio fue derogado por medio del Artículo 77 de la Ley 1739 (2014). Entre las razones por las que se eliminó este beneficio se encuentran: la necesidad fiscal por parte del gobierno nacional, los costos y problemas asociados al proceso de devolución y la existencia de otras alternativas para estimular la utilización de dinero plástico y servicios de banca móvil, ofrecidas por las entidades financieras (Asobancaria, 2016a). Aunque fue una medida transitoria, la devolución de los puntos de IVA fue un estímulo directo por el uso de tarjetas crédito y débito y su derogación obligó a la formulación de políticas privadas por parte de instituciones financieras, para incentivar a sus clientes con estrategias como: puntos por todo, sorteos, descuentos en franquicias aliadas, millas para viajes, entre otros.

La Ley 1676 (2013) o ley de garantías mobiliarias tiene por finalidad apoyar a empresas y personas con trámites sencillos para acceder a créditos financieros. Esta legislación permite la eliminación de formalidades contractuales, ampliando el número de bienes, derechos o acciones que puedan ser objeto de garantía mobiliaria. Esta normatividad fue aplaudida por los organismos multilaterales, pues en el 2016 Colombia mejoró su posición en el Reporte Mundial de Competitividad.

Con la expedición del Decreto 2654 de 2014, mediante el cual se crea la categoría de crédito de consumo de bajo monto. A través de este decreto las entidades financieras pueden aprobar de manera expedita créditos por un monto máximo de dos salarios mínimos legales mensuales vigentes (SMLMV), un plazo de hasta 36 meses y sin necesidad de constituir garantías. Adicionalmente, esta normatividad aprueba el esquema institucional de la estrategia de inclusión financiera. Se propone la estructura orgánica para la orientación, dirección y operación de la política (Ministerio de Hacienda de Colombia, 2016).

La Ley 1753 (2015) (Plan Nacional de Desarrollo 2014-2018) adicionó una serie de metas que complementan el esquema de monitoreo y seguimiento de los avances de la inclusión financiera (Ministerio de Hacienda de Colombia, 2016). También dicta las medidas tendientes a promover el acceso a los servicios financieros transaccionales, por tanto, crea las Sociedades Especializadas en Depósitos y Pagos Electrónicos 
(Sedpe), destinadas a promover la inclusión financiera a través de productos financieros transaccionales, como transferencias, pagos y giros. Las Sedpe pueden utilizar corresponsales bancarios, pero de ninguna manera pueden emitir créditos (Ministerio de Hacienda de Colombia, 2016).

Con el fin de materializar las metas propuestas en el Plan Nacional de Desarrollo 2014-2018, Asobancaria formuló El Proyecto F; una estrategia que involucra el sector público y privado con el objetivo de disminuir el uso del efectivo, masificar los medios de pago electrónicos e intensificar la inclusión financiera. Estas metas incluyeron la reducción de la informalidad, el aumento de la educación financiera y el fomento del uso de las tecnologías financieras disponibles (Montoya, Rodríguez \& Borja, 2017, p. 407).

El Decreto 587 (2016) regula la seguridad de las tarjetas de crédito, en particular, la reversión de los pagos electrónicos, complementando el Artículo 51 de la Ley 1480 (2011) o Estatuto del consumidor. Adicionalmente, para estimular el crédito de consumo el gobierno decidió cambiar la periodicidad de la certificación de la tasa de usura que rige para los créditos de consumo. Asobancaria en su momento afirmó que no se encontraba de acuerdo que esta medida representara beneficios para los consumidores (Asobancaria, 2017). Este comentario del gremio expresaba su inconformidad en cuanto que el gobierno perentoriamente modificara la tasa de interés de colocación.

En el año 2017, la Circular Externa 026 de 2017 modifica las condiciones de crédito según la capacidad de pago del deudor para que no esté reportado a las centrales de riesgo mientras normaliza su situación financiera, esto se debe al ciclo económico por el que atravesaba el país (Superintendencia Financiera de Colombia, 2017a). Las disposiciones de esta circular siguen vigentes.

En años recientes, el gobierno colombiano apostó por la mejora en el ambiente inversionista, en fuentes de financiación más incluyentes que permitían seguir avanzando en la reducción del desempleo, la pobreza y la inequidad como parte de los compromisos por su reciente ingreso a la OCDE. Así, en el informe de los resultados del Reporte Mundial de Competitividad 2015-2016 Colombia ascendió de posición a partir de la mejora obtenida en los factores que evalúan la eficiencia (subió del 
lugar 63 al 61, en el 2016 se evaluaron 140 economías). Entre los aspectos considerados en el indicador de eficiencia está el desarrollo del mercado financiero, en el cual obtiene el mejor desempeño pasando del lugar 70 al 25 (entre 140 países) lo que contribuyó significativamente a consolidar la fluidez del mercado financiero, al facilitar el otorgamiento de préstamos (Departamento Nacional de Planeación de Colombia, 2017). No obstante, en el 2017 la competitividad del país descendió (ocupó el puesto 66 de 137 economías), principalmente por el retroceso en: institucionalidad, infraestructura y ambiente macroeconómico - déficit fiscal y corrupción son los factores que impactan negativamente el desempeño competitivo del país-.

En la competitividad nacional, el mercado financiero sigue siendo un frente que mantiene su estabilidad gracias a las políticas que facilitan la inclusión financiera (iniciativa respaldada por los organismos multilaterales). Desde 2006, el gobierno nacional colombiano ha venido estimulando propuestas para el uso de servicios financieros; en particular en el sector rural, para personas de bajos ingresos, pequeńas y medianas empresas y en la promoción de la educación financiera para tener usuarios más calificados e idóneos en estos servicios (Ministerio de Hacienda de Colombia, 2016).

La escasa educación financiera se ha convertido en un tema político, pues los riesgos son preocupantes frente al debilitamiento del estado de bienestar y la desregulación de los mercados financieros; las personas suelen quedarse sin ahorros, sin pensión por vejez y sobreendeudadas por la inclusión financiera. De esta manera, la OCDE en las pruebas PISA incluyó un módulo de alfabetización financiera, posiblemente para difundir la idea de que la educación financiera es tan importante como las habilidades de lenguaje y matemáticas. El concepto de educación financiera implica que las personas se enfrentan a productos financieros complejos, por tanto, no puede limitarse a una visión tradicional de los presupuestos familiares, donde no se debe de gastar por encima de los ingresos. Los individuos deben tener en cuenta su ciclo de vida: ahorrar cuando sea necesario, pedir prestado en el momento adecuado, prepararse financieramente para un nuevo bebé o la separación de una pareja, acumular riqueza para la jubilación. Pero también los riesgos potenciales o las contingencias de la vida que podrían enfrentar: enfermedad, desem- 
pleo o quiebra (Lazarus, 2016, pp. 1-5).

\section{Las instituciones a cargo de ampliar el crédito}

En el mercado de tarjetas de crédito se pueden distinguir las entidades que formulan las políticas, la institución que supervisa y controla el mercado, las centrales de riesgo que brindan información sobre los clientes, el gremio y las franquicias.

Entre las entidades que formulan las políticas resaltamos de manera jerárquica el poder público. En el contexto de esta investigación nos interesa la función ejecutiva y legislativa que ejerce el presidente de la República, su gabinete y el Congreso de la República que se encarga de elaborar, interpretar, reformar y derogar las leyes y códigos en todos los ramos de la legislación.

El Ministerio de Hacienda y Crédito Público, es la cartera del ejecutivo encargada de la preparación de las leyes y decretos, la regulación de crédito público, la política financiera, cambiaria, monetaria y crediticia, sin perjuicio de las atribuciones conferidas a la Junta Directiva del Banco de la República y de conformidad con la Constitución Política y la Ley (Ministerio de Hacienda y Crédito público, 2017, p. 1).

El Banco de la República de Colombia, además de ejercer las funciones de banca central, se encarga de ser prestamista y banquero de los establecimientos de crédito y servir como agente fiscal del Gobierno (Banco de la República de Colombia, 2013, p. 1).

La Superintendencia Financiera de Colombia, es la entidad que supervisa y controla las entidades financieras bancarias. Su misión es preservar la confianza pública y la estabilidad del sistema financiero. Entre sus objetivos principales está "que todas las personas, especialmente las más pobres, tengan acceso a productos y servicios financieros formales acordes a sus necesidades" (Superintendencia Financiera de Colombia, 2017b, p. 1).

La Superintendencia Financiera de Colombia (2017), a través de la Dirección de Protección al Consumidor Financiero, ha dispuesto que cada entidad financiera vigilada tenga un Defensor del Consumidor financiero, el cual responde consultas escritas, telefónicas o personales, en el marco de la Ley 1328 de 2009 o ley del Consumidor Financiero.

Es de aclarar, que la Superfinanciera no vigila a todos los emisores de tarjetas de crédito, solo se encarga de controlar a aquellas entidades que 
hacen captación y colocación de sus recursos. De esta manera, existen entidades financieras no bancarias, que corresponden a aquellas instituciones privadas que colocan sus propios recursos a través de productos como tarjetas de crédito, créditos de consumo o libranzas, sin recurrir a la captación de dinero del público. Estas entidades son vigiladas por la Superintendencia de Sociedades y la Superintendencia de Industria y Comercio.

La Asociación Gremial Financiera, Asobancaria, es la asociación representativa del sector financiero colombiano. Su objetivo es promover el desarrollo del sector bancario, defender los intereses de la industria bancaria en Colombia y establecer un enlace permanente y estable con las autoridades gubernamentales (Asobancaria, 2016b, p. 2).

Entre las entidades que brindan información sobre los clientes se encuentra TransUnion LLC (2017), que se encarga de proporcionar a los emisores de crédito en todo el país una fuente de información de crédito rápida y valiosa. En febrero de 2016, TransUnion adquirió la sociedad colombiana CIFIN S.A. Adicionalmente, otra institución que suministra información sobre los deudores es DataCrédito Experian (2016); es la central de información crediticia que provee una "base de datos con información de identificación, localización demográfica, hábito de pago y nivel de endeudamiento de personas naturales y jurídicas" (DataCrédito Experian, 2016, p. 1).

Seguidamente, Incocredito se encarga de la investigación, información y control de tarjetas crédito y débito. Es una asociación especializada en la seguridad de la industria de medios de pago en Colombia, ofrece sistemas de pago de bajo valor en todas las etapas del ciclo integral de prevención y control del fraude. (Incocredito, 2017, p. 1).

Las franquicias que operan en Colombia respaldando tarjetas crédito y débito son: CredibanCo Visa que actualmente le apuesta a la formalización e inclusión financiera, a la optimización de portafolios para el sector financiero y los comercios (CredibanCo, 2013, p. 1). Redeban Multicolor MasterCard que tiene como objetivo facilitar el desarrollo de la industria de pagos; su apuesta actual es la implementación de innovaciones financieras que permitan a sus usuarios mayor servicio en pagos electrónicos (Redeban Multicolor, 2016, p. 1). American Express, empresa global de servicios, desde 2002 está asociada con Bancolombia y en el 2017 el Banco Colpatria es emisor de esta franquicia (American Express, 2016, 
p. 1). Diners Club Colombia, aunque fue la primera tarjeta de crédito del país, hoy el único banco que emite tarjetas con esta franquicia es el Banco Davivienda (Diners Club International, 2014, p. 1).

La tabla 1 presenta el impacto de las políticas públicas con las instituciones que participan en el mercado de las tarjetas de crédito.

\section{Tabla 1. Matriz de instituciones QUe participan en el Mercado} DE LAS TARJETAS DE CRÉDITO

\begin{tabular}{|c|c|c|}
\hline Instituciones & Funciones Relacionadas & Relación con las Políticas públicas \\
\hline \begin{tabular}{|l|} 
Poder Legislativo \\
(Constitución Política de \\
Colombia, 1991) \\
\end{tabular} & $\begin{array}{l}\text { Se encarga de elaborar, interpretar, } \\
\text { reformar y derogar las Leyes y Códigos } \\
\text { en todos los ramos de la Legislación. }\end{array}$ & $\begin{array}{c}\text { Esta institución formula las políticas públicas relacionadas con la } \\
\text { tarjeta de crédito, de esta manera se despliegan las intervenciones que } \\
\text { hace el Estado }\end{array}$ \\
\hline $\begin{array}{l}\text { Ministerio de Hacienda y } \\
\text { Crédito público } \\
\text { (Ministerio de Hacienda y Crédito } \\
\text { público, 2017a) }\end{array}$ & $\begin{array}{l}\text { Su función es definir, formular y ejecutar } \\
\text { la política económica. }\end{array}$ & $\begin{array}{l}\text { Esta institución formula y ejecuta las políticas públicas relacionadas } \\
\text { con la tarjeta de crédito. }\end{array}$ \\
\hline $\begin{array}{l}\text { Superintendencia Financiera } \\
\text { (Superintendencia Financiera de } \\
\text { Colombia, 2017c) }\end{array}$ & $\begin{array}{l}\text { Se encarga de vigilar el sector financiero } \\
\text { en virtud de las políticas del Estado. }\end{array}$ & $\begin{array}{c}\text { Esta entidad hace cumplir las normatividades que aplican para las } \\
\text { tarjetas de crédito. Por su capacidad de sancionar es vital para ejecutar } \\
\text { las políticas públicas en materia financiera. }\end{array}$ \\
\hline Asobancaria & Su objetivo es representar el sector & \\
\hline (Asobancaria, 2016a) & $\begin{array}{l}\text { financiero colombiano. Persigue el } \\
\text { desarrollo del sector bancario y } \\
\text { financiero. }\end{array}$ & $\begin{array}{l}\text { autoridades gubernamentales. En Colombia es un grupo poderoso para } \\
\text { defender los intereses del sector financiero. }\end{array}$ \\
\hline $\begin{array}{l}\text { TransUnion, Data Crédito } \\
\text { Experian. } \\
\text { (TransUnion LLC, 2017), } \\
\text { (DataCrédito Experian, 2016) }\end{array}$ & $\begin{array}{l}\text { Son las centrales de Riesgo del país, pues } \\
\text { facilitan información de las actividades } \\
\text { financieras de los usuarios de productos } \\
\text { bancarios y otros. }\end{array}$ & $\begin{array}{l}\text { Se encargan de brindar información sobre el comportamiento } \\
\text { crediticio de los clientes de tarjetas de crédito. Actualizan el sistema } \\
\text { de información para que las entidades financieras puedan expedir } \\
\text { productos financieros. }\end{array}$ \\
\hline \begin{tabular}{|l} 
Visa, Diners Club, American \\
Express y Master Card \\
(CredibanCo, 2013), (Diners Club \\
International, 2014a), (American \\
Express, 2016a), (Redeban \\
Multicolor, 2016) \\
\end{tabular} & $\begin{array}{l}\text { Permiten a las entidades financieras } \\
\text { emitir tarjetas de crédito bajo sus } \\
\text { franquicias. }\end{array}$ & $\begin{array}{l}\text { Las políticas públicas actuales benefician a estas corporaciones para } \\
\text { alcanzar más cuota de mercado. Estas franquicias contribuyen con } \\
\text { políticas privadas que flexibilizan las condiciones para adquirir tarjeta } \\
\text { de crédito. }\end{array}$ \\
\hline
\end{tabular}

Fuente: elaboración propia con datos de las instituciones.

\section{Efectos de las políticas públicas: ¿̨una expansión problemática?}

Es posible afirmar que las norma tividades que se han expedido desde hace más de dos décadas han influido en que más personas puedan acceder a productos crediticios. En Colombia las cifras oficiales muestran que el número de tarjetas de crédito para el año 2002 ascendía a 1,9 millones, mientras que en junio de 2018 las tarjetas de crédito activas corresponden a 15 millones, lo cual revela un crecimiento de 49,2\% promedio anual. Esta tendencia ha sido similar en el número de personas (total de tarjetas de crédito antiguas y nuevas); el ańo de mayor crecimiento en la serie analizada es el 2009 con un 23,3\%, seguido por 2014 con 16,6 \% y 
2011 con 14,6 \% (Ver gráfico 1). Estos datos cobran mayor relevancia si se analizan con relación a la Tasa Global de Participación — se trata de una medida más ajustada entre la población económicamente activa y la población en edad de trabajar-.

Se usa este indicador con el objetivo de reflejar aquellas personas que por su condición laboral podrían acceder a un instrumento crediticio más expeditamente. De esta manera contrasta que, en la serie analizada el 2009 se presenta el mayor crecimiento de número de personas con tarjetas crédito, mientras que la TGP solo crece un 1,7\%. Llama la atención que los años que más asciende este último indicador son: 2011 con $3 \%$ y 2012 con $2,8 \%$, los periodos siguientes la tendencia es negativa. Podría notarse que a pesar que la Tasa Global de Participación muestra leves crecimientos en pocos periodos, el ascenso anual de personas con tarjeta de crédito es constante.

\section{Gráfico 1. Relación de número de personas con tarjetas de CRÉDITO EXISTENTES Y TGP POR AÑO}

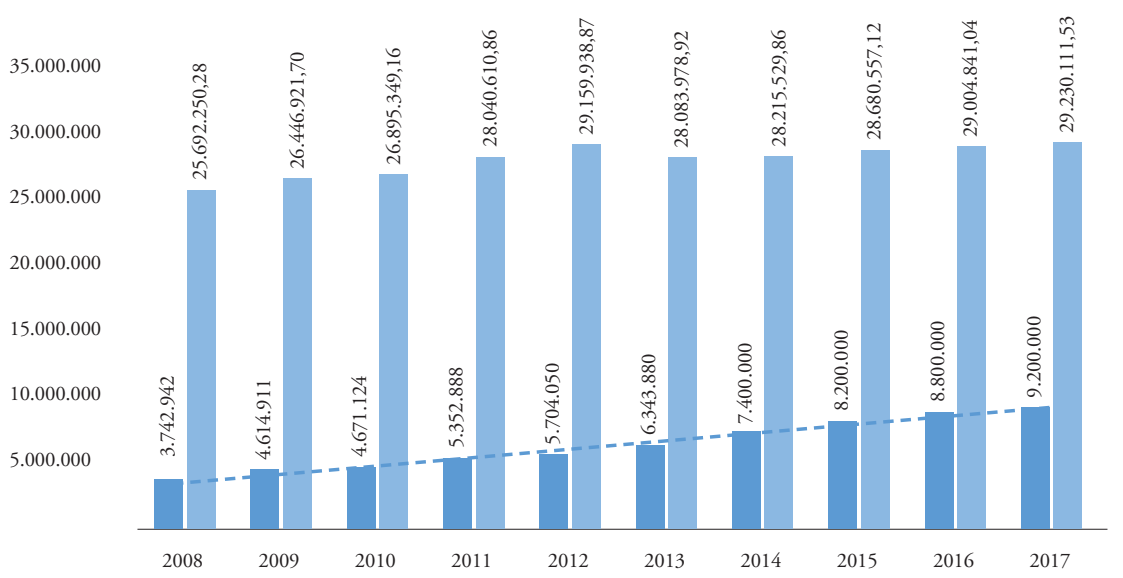

TGP refleja la presión de la población sobre el mercado laboral. Es la relación entre la población económicamente activa y la población en edad de trabajar. TGP: PEA/PET. Fuente: elaboración propia con datos semestrales de Asobancaria (2013); Superintendencia Financiera de Colombia y Banca de Oportunidades (2018), Dane (2018).

Según datos de la Superintendencia Financiera de Colombia las tarjetas de crédito vigentes en 2018 con mayor participación en el mercado son: Colpatria con $18,2 \%$, esta entidad financiera posee una alianza 
con los supermercados Jumbo y Metro. En segundo lugar, la tarjeta de crédito Tuya de Almacenes Éxito con 15.2 \%. Bancolombia con 14,7\% y tarjeta de crédito Falabella con $10.7 \%$ de un total de más 15 millones de tarjetas de crédito activas. El liderazgo lo ostenta el grupo Bancolombia, pues la tarjeta Tuya es emitida por una corporación de su propiedad, en total su participación es de $30 \%$ (Superintendencia Financiera de Colombia, 2018).

Con el propósito de relacionar las leyes y el comportamiento de las tarjetas de crédito se elabora la figura 2 que refleja las políticas emitidas entre los ańos 2006 y 2017. Estas normatividades incluyen un acervo de Planes Nacionales de Desarrollo (3 en total), Conpes (1), Leyes, Decretos y Circulares que facilitaron el crédito en Colombia.

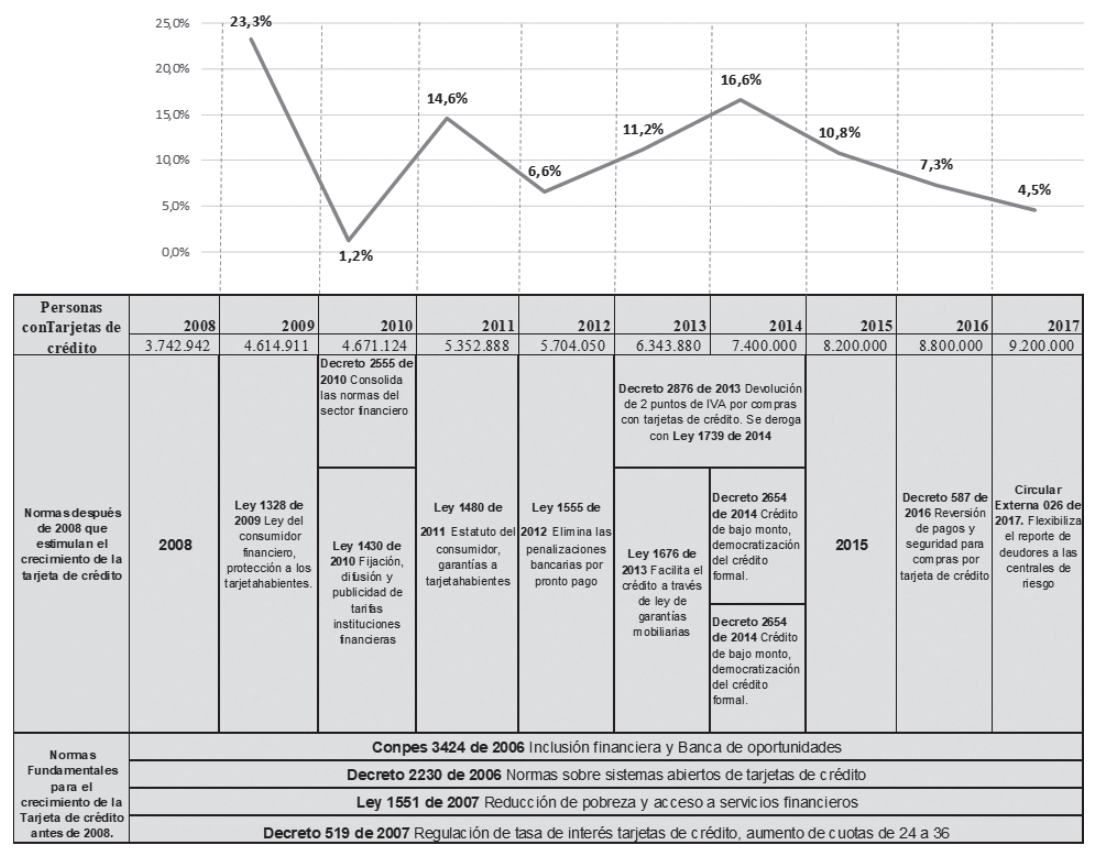

Figura 2. Relación entre las políticas asociadas al uso de la tarjeta de crédito y el crecimiento de las tarjetas de crédito existentes en el mercado.

Fuente: elaboración propia (2017) con datos de Superintendencia Financiera de Colombia, Asobancaria, leyes, decretos y otros.

El crecimiento en 2009 (23.3 \%) estuvo precedido de un fuerte andamiaje normativo entre los años 2006 y 2008, en este periodo se encuentran: 
Conpes 3424 (2006) donde se introduce la "inclusión financiera y la banca de oportunidades", Decreto 2230 (2006) el cual regula las normas sobre los "sistemas abiertos de tarjetas de crédito", Ley 1151 (2007) Plan Nacional 2006-2010; reconocida como la Ley de "reducción de pobreza y acceso a servicios financieros", por último el Decreto 519 (2007) que regula la tasa de interés e incrementa el número de plazos para diferir los pagos de la tarjeta de crédito (de 24 a 36). Se aclara que las nuevas condiciones de estos reglamentos siguen vigentes hasta la fecha. La desregulación de las tasas de interés y los requisitos de capital hizo que los préstamos al consumidor fueran más lucrativos y creó más competencia entre los prestamistas para expandir el mercado (Carruthers y Airovich, 2010).

La Ley 1328 (2009) o "Ley del consumidor financiero" da lugar a que se proteja de manera férrea a los tarjetahabientes, no obstante, el crecimiento de las personas con tarjeta de crédito para el 2010 es de $1.2 \%$, esto puede deberse a la coyuntura económica ocasionada por la crisis inmobiliaria, aunque se puede adicionar que las políticas públicas entre 2008 y 2009 fueron pocas, esto pudo repercutir en los resultados para el año 2010. En el año 2011 se presenta una recuperación en este medio de pago, representado en $14.6 \%$, esto puede ser consecuencia de la expedición del Decreto 2555 (2010) que consolida las normas del sector financiero y la Ley 1430, (2010) que tiene por finalidad la "Fijación, difusión y publicidad de tarifas instituciones financieras". En 2012, se refleja un $6.6 \%$ de incremento en las personas con tarjetas de crédito, este resultado se puede relacionar con la expedición de la Ley 1450 (2011) o el "Estatuto del consumidor", normatividad que establece protecciones y garantías a los tarjetahabientes a través de la figura del consumidor financiero.

El desempeño en las tarjetas de crédito en el 2013 evidencia un $11.2 \%$ de incremento en el desembolso de tarjetas de crédito, gracias a la Ley 1555 (2012) la cual "elimina las penalizaciones bancarias por pronto pago". Así un usuario de tarjeta de crédito puede diferir las cuotas en los plazos que desee y no pagará costos adicionales si su flujo de caja permite pagar antes. La Ley 1676 (2013) facilita el crédito para PYMES y personas, pues flexibiliza la forma de otorgar los créditos a través de garantías mobiliarias, esto incide en que en el año 2014 el comportamiento tendencial se posicione en $16,6 \%$.

En 2013 también se dio un estímulo trascendente para el uso de la tarjeta de crédito, fue la posibilidad para los tarjetahabientes de que por 
cada compra con tarjeta de crédito y débito se le devolvieran dos puntos porcentuales de IVA, esto fue posible a través del Decreto 2876 (2013), que lamentablemente fue derogado por la Ley 1739 (2014). Las entidades emisoras de tarjetas de crédito se vieron obligadas a buscar tácticas individuales duraderas para promover los nuevos usuarios y el consumo a través del dinero plástico. Entre estas estrategias está la acumulación de millas para viajes, descuentos en productos en cadenas aliadas y puntos redimibles por dinero o premios.

En 2014, el Decreto 2654 o reconocido como Crédito de bajo monto o democratización del crédito formal, aunque no fue incluida la tarjeta de crédito para esta regulación, las entidades financieras aprovecharon la emisión de estos microcréditos para personas de bajos ingresos para otorgar tarjetas de crédito. Quizá esta regulación haya incidido para el crecimiento de número de personas con tarjetas de crédito en 2015 (10,8\%); dado que muchas veces la asignación de un microcrédito va acompañada con la expedición de una tarjeta de crédito. En 2015 no hubo políticas con respecto a la flexibilización del acceso crédito, es posible que el descenso en el aumento sostenido de más de dos dígitos con el que venía el mercado de las tarjetas de crédito se haya estancado en 2016 y 2017, 7,3 \% y 4,5\% respectivamente. En 2016 a través del Decreto 587 (2016) se permite la reversión de pagos y seguridad para compras por tarjeta de crédito, aunque es una medida beneficiosa para las personas que ya tienen el plástico, no es una normatividad encaminada a estimular nuevos tarjetahabientes. De manera similar, ocurre con la Circular Externa 026 de 2017, que trae efectos positivos sobre las personas que ya poseen una obligación crediticia, aunque sus resultados se verán reflejados en 2018.

El reporte de inclusión financiera 2017 revela que el número de personas con productos de crédito ha crecido en los últimos años. Se destaca que los productos de crédito más utilizados el año pasado son la tarjeta de crédito y el crédito de consumo. Incluso, la tarjeta de crédito fue el segundo producto de ingreso al mercado financiero después de la cuenta de ahorro. Entre 2016 y 2017, la distribución por edad de los adultos con tarjeta de crédito vigente tenía entre 41 y 65 años, equivalente a una participación de $45 \%$, seguidos por aquellos entre 26 y 40 años, que representan el $38 \%$. En 2017 se realizaron 277 millones de operaciones de tarjeta de crédito por $\$ 23$ billones de dólares, valores que representaron aumentos de $9 \%$ en 
número y $6 \%$ real en monto frente al 2016. El incremento de datafonos incentiva las transacciones con tarjetas; en el 2016 el crecimiento fue de 10,7 \% y con respecto al 2015 fue de 27,2 \% (Superintendencia Financiera de Colombia y Banca de Oportunidades, 2018).

Retomando el caso mencionado al inicio, no se puede perder de vista que Lucy ha experimentado una creciente dependencia de los mercados financieros para llevar a cabo su proyecto de vida. Puede pensarse que todo el acervo de normatividades que se han expedido para flexibilizar las condiciones crediticias tuvo una especie de impacto en su vida cotidiana o lo que algunos expertos en las finanzas personales denominan financiarización (Blackburn, 2006; Lazzarato, 2011; Van der Zwan, 2014; Lapavitsas, 2016). Por ejemplo, se ha visto beneficiada por el Decreto 519 (2007) que reguló la tasa de interés de usura e incrementó el número de plazos para diferir los pagos de la tarjeta de crédito (de 24 a 36 meses); ya que ella usa frecuentemente su tarjeta de crédito - mecanismo que prefiere en vez de deudas con familiares o con usureros-, difiere a varias cuotas y si es posible anticipa el pago. En cuanto a esta última práctica, la Ley 1555 (2012) eliminó las penalizaciones bancarias por pronto pago; es así como ella salda sus cuentas financieras onerosas cuando su flujo de caja lo permite sin incurrir en costos adicionales. De la misma forma, la Ley 1676 (2013) facilitó el crédito para personas al otorgar desembolsos a través de garantías mobiliarias alcanzables, lo que permitió que Lucy pudiera acceder a instrumentos crediticios con solo demostrar unos mínimos ingresos. Estas y otras leyes reflejan la incidencia que tienen las políticas públicas sobre la vida de las personas que acceden a créditos formales. Es así como la expansión de las finanzas ha servido como una política pública social y económica por la cual se adelantan recursos futuros y se posponen en el tiempo conflictos distributivos; de modo que a partir de hogares de ingresos bajos y medios estas políticas se encaminan a crear sujetos económicamente viables (González, 2018, p. 883).

\section{Reflexiones finales}

El gobierno ha formulado políticas sociales que facilitan una nueva dinámica del sistema financiero y bancario que redefine el lugar de los sectores de bajos recursos en el mercado del crédito. Si bien toda esta estructura normativa puede ser una consecuencia adyacente del fuerte 
vínculo entre el sistema legal y el desarrollo económico (La Porta, Lopez-de-Silanes, Shleifer y Vishny, 1998, p. 1152). Esto ha incidido en la flexibilización de las condiciones de aprobación de créditos para las clases de menos ingresos, los bancos han modificado la tecnología de evaluación de los tomadores de crédito también llamada credit scoring o rating (Carruthers y Airovich, 2010; Wilkis, 2014; Rona-Tas y Guseva, 2018). Lo anterior, sumado a las innovaciones en el negocio crediticio, desde las tarjetas de crédito que simplificaron el endeudamiento hasta herramientas de altas finanzas como la securitización (o titularización) de la deuda del consumidor, han contribuido a la consolidación del negocio financiero. Por otro lado, las entidades financieras se enfrentan a procesos como: la pérdida de clientes corporativos, los avances tecnológicos, la regulación de los mercados financieros acompanada paradójicamente de desregulación, todo esto pone de relieve la creciente disponibilidad de crédito en términos tanto de su cantidad como de su alcance social (Rona-Tas y Guseva, 2018, p. 3).

De la misma forma, se puede observar en la última década un incremento de la publicidad de las instituciones financieras, bancos y franquicias de tarjetas de crédito en programas televisivos dirigidos a una audiencia popular o el despliegue de oferta préstamos directos a través de agentes comerciales en los supermercados o almacenes de cadena (Müller, 2014, p. 5). En la actualidad es el endeudamiento privado y no la deuda pública lo que mantiene la economía en funcionamiento, esto desencadena que el sistema financiero dependa cada vez más del crédito de consumo. Con esta economía de deuda, los Estados obtienen más aporte al PIB por los rendimientos financieros y el consumo, que por la actividad industrial (Lazzarato, 2011; Lapavitsas, 2016; Rona-Tas y Guseva, 2018). Entonces el consumo le da un espaldarazo al crédito; la demanda de nuevos artículos hace posible la industria del crédito al consumo. La incoherencia derivada de una sensación de retraso respecto a los estándares de consumo establecidos por el grupo social se contrarresta con el crédito al consumo que permite a las personas "ponerse al día”. Para que esto ocurra, los consumidores deben sentirse atraídos por los niveles más altos de consumo y las instituciones financieras deben desarrollar tecnologías de cálculo de riesgo que hagan que los préstamos al consumidor sean un negocio rentable (Becker, 2016, p. 206). 
Una vez que una persona o empresa está endeudada - para invertir o para consumir - el crédito tiene varios efectos: el endeudamiento excesivo puede incentivar el riesgo moral ya que algunas personas que no poseen ingresos corrientes ni bienes para responder por sus deudas pueden caer en default o seguir endeudándose mientras el sistema financiero se lo permita. El endeudamiento, como en el caso de dońa Lucy, puede tener un efecto disciplinario: presiona al deudor para que actúe de manera que repague el préstamo. Una economía cada vez más dominada por las finanzas requiere comportamientos y formas institucionales que reflejen la estabilidad del sistema financiero, ejerciendo presión sobre la economía y la sociedad. Por lo tanto, el crédito puede verse como una forma de gobernabilidad y dominación (Bourdieu, 2005 citado en Beckert, 2016, p. 118). De hecho, estas prácticas de disciplina crean un nuevo tipo de sujeto social digno de crédito, caracterizado por el cumplimiento puntual de sus obligaciones con los bancos o con otros acreedores. Por todo lo anterior, devolver el dinero prestado es simplemente un asunto de moralidad (Graeber, 2012, p. 15). Para Lucy, pagar sus obligaciones a las entidades financieras es un asunto prioritario en su presupuesto mensual, ya que dejar de pagar implicaría cerrar las puertas en el sistema financiero para acceder ingresos futuros. No obstante, su vulnerabilidad laboral, Lucy es una cliente con una calificación de riesgo intachable; este tipo de comportamiento puede coadyuvar a incrementar la confianza que la institucionalidad financiera colombiana ha depositado en los clientes de bajos recursos, lo que quizá puede explicar las condiciones cada vez más flexibles para adquirir créditos.

\section{Referencias}

AFI Alliance for Financial Inclusion. (2013). Empoderamiento del consumidor y conducta del mercado Estrategias nacionales de educación financiera. Recuperado de http://www.afi-global.org/publications

American Express. (2016). Acerca de American Express Colombia. Recuperado 2 de octubre de 2017, de https://www.americanexpress. $\mathrm{com} / \mathrm{co} /$ network/content/about-american-express.html

Asobancaria. (2013). Informe Semestral de Inclusión financiera. Recuperado 2 de septiembre de 2017 de: https://www.asobancaria. com/2016/01/28/informe-semestral-de-inclusion-financiera/ 
Asobancaria. (2016a). ¿Y qué pasó con la devolución de los puntos del IVA? Recuperado de http://www.asobancaria.com/sabermassermas/ y-que-paso-con-la-devolucion-de-los-\%2509puntos-del-iva/

Asobancaria. (2016b). ¿Quiénes somos? Recuperado 2 de septiembre de 2017, de http://www.asobancaria.com/quienes-somos/

Asobancaria. (2017). Edición 1102. Reflexiones en materia detasas de interés y usura. Recuperado de http://www.asobancaria.com/2017/08/14/ edicion-1102-reflexiones-en-materia-de-\%2509tasas-de-interesy-usura/

Banco de la República de Colombia. (2013). ¿Qué Hacemos? Recuperado 17 de septiembre de 2017, de http://www.banrep.gov.co/es/ el-banco/que-hacemos

Banco Mundial. (2017). Financial Inclusion. Recuperado de http://www. worldbank.org/en/topic/financialinclusion/overview\#2

Beckert, J. (2016). Money and Credit, In Imagined futures: fictional expectations and capitalist dynamics. Cambridge, Reino Unido: Harvard University Press. 97-130.

Blackburn, R. (2006). Las finanzas y la cuarta dimensión. New Left Review (español), (39), 37-70.

Carruthers, B. y Ariovich, L. (2010). Money and Credit. A Sociological Approach. Cambridge, Reino Unido: Polity.

Chaves, L. (2013). Regulación de las tarjetas de crédito en Costa Rica. Revista de Ciencias Sociales, 1(139), 151-160. doi: https:/doi.org/ 10.15517/rcs.v0i139.11361

CredibanCo. (2013). ¿Quiénes somos? Recuperado 2 de septiembre de 2017, de https://www.credibanco.com/credibanco/quienes-somos

Dane, (2018). Boletín Técnico GEIH por Departamento 2017. Recuperado 4 de septiembre de 2019, de https://www.dane.gov.co/files/investigaciones/boletines/ech/ml_depto/Boletin_dep_17.pdf

DataCrédito Experian. (2016). ¿Quiénes somos? Recuperado 17 de septiembre de 2017, de https://www.datacredito.com.co/quienessomos.html

Departamento Nacional de Planeación de Colombia. (2017). Sintesis de Resultados del Reporte global de Competitividad 2015-2016, Foro Económico Mundial. Recuperado de https://colaboracion.dnp.gov.co/CDT/Desarrollo Empresarial/Resultados Competitividad FEM 2015.pdf 
Departamento Nacional de Planeación de Colombia. (2018). Sintesis de Resultados del Reporte global de Competitividad 2016-2017. Foro Económico Mundial.

Diners Club International. (2014). ¿Quiénes somos? Recuperado 2 de octubre de 2017, de https://www.mundodinersclub.com/quienes-somos-colombia.html

Global Findex. (2015). Datos de Inclusión Financiera. Recuperado 23 de agosto de 2017, de http://databank.worldbank.org/data/reports. aspx?source $=1228 \#$

González, F. (2018). Crédito, deuda y gubernamentalidad financiera en Chile. Revista mexicana de sociología, 80(4), 881-908. doi: http:// dx.doi.org/10.22201/iis.01882503p.2018.4.57798

Graeber, D. (2012). En deuda: una historia alternativa de la economía. Barcelona, España: Ariel.

Han, C. (2011). Symptoms of another life: time, possibility, and domestic relations in Chile's credit economy. Cultural Anthropology, 26(1), 7-32. doi: https://doi.org/10.1111/j.1548-1360.2010.01078.x

Incocredito. (2017). ¿Quiénes somos? Recuperado de https://www.incocredito.com.co/index.php/nosotros.html

La Porta, R., Lopez-de-Silanes, F., Shleifer, A. \& Vishny, R (1998). Law \& Finance. Journal of Political Economy, 106(6), 1113-1155.

Lapavitsas, C. (2016). Beneficios sin producción. Cómo nos explotan las finanzas. Madrid, España: Traficantes de sueños.

Lazarus, J. (2016). The issue of financial literacy: Low finance between risk and morality. Economic Sociology the european electronic newsletter, Max Planck Institute for the Study of Societies 7(3), 27-34. Recuperado de: https://EconPapers.repec.org/RePEc:zbw:econso:156077

Lazzarato, M. (2011). The making of indebted man: An essay on the Neoliberal Condition. Amsterdam, Holanda: Agence litteraire Pierre Astier $\&$ Associés

Ministerio de Hacienda de Colombia. (2016). Estrategia nacional de inclusión financiera. Recuperado de http://www.minhacienda. gov.co/HomeMinhacienda/ShowProperty?nodeId=\%2FOC\%09S\%2FP_MHCP_WCC-041673\%2F\%2FidcPrimaryFile\&revision=latestreleased 
Ministerio de Hacienda y Crédito público. (2017). Acerca del Ministerio. Recuperado 2 de octubre de 2017, de http://www.minhacienda. gov.co

Montoya G., Rodríguez N. \& Borja, W. (2017). La estrategia interinstitucional para la reducción del uso del efectivo y la masificación de los medios de pago electrónicos. En C. Tamayo \& J. Malagón J. (Eds). Ensayos sobre inclusión financiera en Colombia. Banco Interamericano de Desarrollo, 359-412.

Müller, L., (2014). Negotiating debts and gifts: financialization policies and the economic experiences of low-income social groups in Brazil. Vibrant: Virtual Brazilian Anthropology, 11(1), 191-221. doi: http:// dx.doi.org/10.1590/S1809-43412014000100007

Pachas, P. (2011). Tarjetas de crédito en aumento: Sobreendeudamiento, alto riesgo ¿la regulación? Gestión en el Tercer Milenio, 14(27), 33-45.

Pereyra, G. (2011). Desarrollo de los Medios de Pagos Electrónicos en caso particular de las tarjetas de pago de Débito y Crédito (tesis de pregrado). Universidad de la República, Montevideo, Uruguay.

Redeban Multicolor. (2016). ¿Quiénes somos? Recuperado 2 de septiembre de 2017, de https://www.rbmcolombia.com/wps/portal/ index/institucional/quienesomos

Rona-Tas, A., \& Guseva, A. (2018). Consumer Credit in Comparative Perspective. Annual Review of Sociology, 44, 55-75. doi: https://doi. org/10.1146/annurev-soc-060116-053653

Superintendencia Financiera de Colombia y Banca de Oportunidades. (2017). Reporte de Inclusión financiera 2016. Recuperado el 3 de septiembre de 2017, de: http://bancadelasoportunidades.gov.co/es/ reportes/617

Superintendencia Financiera de Colombia y Banca de Oportunidades. (2018). Reporte de Inclusión financiera 2017. Recuperado el 16 de septiembre de 2018, de: http://bancadelasoportunidades.gov.co/ index.php/es/reportes/401

Superintendencia Financiera de Colombia. (2017a). ABC Modificación en las condiciones del crédito según capacidad de pago del deudor. Recuperado 3 de octubre de 2017, de https://www.superfinanciera.gov.co/ jsp/loader.jsf?IServicio=Publicaciones\&lTipo=publicaciones\&lFuncion=loadContenidoPublicacion\&id=10090487 
Superintendencia Financiera de Colombia. (2017b). Acerca de la SFC. Recuperado 16 de septiembre de 2017, de https://www.superfinanciera.gov.co/jsp/index.jsf

Superintendencia Financiera de Colombia. (2018). Informe de desembolsos por tipo de crédito e Informe mensual de tarjetas de crédito. Recuperado de https://www.superfinanciera.gov.co/jsp/loader.jsf!Servicio=Publicaciones\&lT\%09ipo=publicaciones\&lFuncion=loadContenidoPublicacion\&id $=60952 \% 09$

TransUnion LLC. (2017). ¿Quiénes Somos? Recuperado 17 de septiembre de 2017, de https://www.transunion.co/quienes-somos/historia

Van der Zwan, N. (2014). Making sense of financialization. Socio-economic review, 12(1), 99-129. doi: https://doi.org/10.1093/ser/mwt020

Wilkis, A. (2014). Sociología del crédito y economía de las clases populares. Revista Mexicana de Sociología, 76(2), 225-252. Recuperado de http://www.redalyc.org/articulo.oa?id=32130485004

\section{Documentos y normas legales}

Constitución Política de Colombia. (1991). Promulgada en la Gaceta Constitucional No. 116 de 20 de julio de 1991. Editado por: Corte Constitucional, Consejo Superior de la Judicatura (Sala Administrativa). Centro de Documentación Judicial (Cendoj). Recuperada de: http://www.secretariasenado.gov.co/senado/basedoc/ constitucion_politica_1991.html

Congreso de la Republica de Colombia (29 de diciembre 2003). Por la cual se establecen normas tributarias, aduaneras, fiscales y de control para estimular el crecimiento económico y el saneamiento de las finanzas públicas [Ley 863] DO: Diario Oficial No. 45415 de diciembre 29 de 2003.

Congreso de la República de Colombia (15 de julio 2009). Por la cual se dictan normas en materia financiera, de seguros, del mercado de valores y otras disposiciones [Ley 1328] DO: Diario Oficial No. 47411 de julio 15 de 2009.

Congreso de la República de Colombia. (26 de junio 2011). Por la cual se expide el Plan Nacional de Desarrollo, 2010-2014 [Ley 1450] DO: Diario Oficial No. 48102 de junio 16 de 2011. 
Congreso de la República de Colombia (12 de octubre 2011). Por medio de la cual se expide el Estatuto del Consumidor y se dictan otras disposiciones [Ley 1480] DO: Diario Oficial No. 48220 de octubre 12 de 2011.

Congreso de la República de Colombia (9 de julio 2012). Por medio de la cual se permite a los consumidores financieros el pago anticipado en las operaciones de crédito y se dictan otras disposiciones [Ley 1555] DO: Diario Oficial No. 48486 de julio 9 de 2012.

Congreso de la República de Colombia (20 de agosto 2013). Por la cual se promueve el acceso al crédito y se dictan normas sobre garantías mobiliarias [Ley 1676] DO: Diario Oficial No. 48888 de agosto 20 de 2013.

Congreso de la República de Colombia (23 de diciembre 2014). Por medio de la cual se modifica el estatuto tributario, la ley 1607 de 2012, se crean mecanismos de lucha contra la evasión y se dictan otras disposiciones [Ley 1739] DO: Diario Oficial No. 49374 de diciembre 23 de 2014.

Congreso de la República de Colombia (9 de junio 2015). Por la cual se expide el Plan Nacional de Desarrollo 2014 2018 “Todos por un nuevo país" [Ley 1753] DO: Diario Oficial No. 49538 de junio 9 de 2015.

Consejo Nacional de Política Económica y Social (Conpes 3424 de 2006) Una política para promover el acceso al crédito y a los demás servicios financieros buscando equidad social. Banca de Oportunidades. Departamento Nacional de Planeación.

Ministerio de Hacienda y Crédito Público (6 de julio 2006). Por el cual se dictan normas sobre publicación de información relacionada con los sistemas abiertos de tarjetas débito y crédito [Decreto 2230] DO: Diario Oficial No. 46321 de julio 6 de 2006.

Presidencia de la República de Colombia. (26 de febrero 2007). Por el cual se determinan las distintas modalidades de crédito cuyas tasas deben ser certificadas por la Superintendencia Financiera de Colombia y se dictan otras disposiciones [Decreto 519] DO: Diario Oficial No. 46554 de febrero 26 de 2007.

Presidencia de la República de Colombia. (24 de julio 2007). Por la cual se expide el Plan Nacional de Desarrollo 2006-2010 [Ley 1151] DO: Diario Oficial No. 46700 julio 25 de 2007. 
Presidencia de la República de Colombia (15 de julio 2010). Por el cual se recogen y reexpiden las normas en materia del sector financiero, asegurador y del mercado de valores y se dictan otras disposiciones [Decreto 2555] DO: Diario Oficial No. 47771 de julio 15 de 2010.

Presidencia de la República de Colombia. (29 de diciembre 2010). Por medio de la cual se dictan normas tributarias de control y para la competitividad [Ley 1430] DO: Diario Oficial No. 47937 de diciembre 29 de 2010.

Presidencia de la República de Colombia (11 de diciembre 2013). Por el cual se reglamenta el Artículo 850-1 del Estatuto Tributario [Decreto 2876] DO: Diario Oficial No. 49001 de diciembre 11 de 2013.

Presidencia de la República de Colombia (17 de diciembre 2014). Por el cual se modifica el Decreto 2555 de 2010 en lo relacionado con el crédito de consumo de bajo monto [Decreto 2654] DO: Diario Oficial No. 49368 de diciembre 17 de 2014.

Presidencia de la República de Colombia (13 de julio de 2015). Por el cual se modifica el Decreto número 2555 de 2010 en lo relacionado con la reglamentación aplicable a las Sociedades Especializadas en Depósitos y Pagos Electrónicos, (SEDPE) y se dictan otras disposiciones [Decreto 1491] DO: Diario Oficial No. 49572 de julio 13 de 2015.

Presidencia de la República de Colombia (11 de abril 2016). Por el cual se adiciona un capítulo al Libro 2 de la Parte 2 del Título 2 del Decreto Único del sector Comercio, Industria y Turismo, Decreto número 1074 de 2015, y se reglamenta el Artículo 51 de la Ley 1480 de 2011 [Decreto 587] DO: Diario Oficial No. 49841 de abril 11 de 2016. 